\title{
Neurovascular Disorder
}

National Cancer Institute

\section{Source}

National Cancer Institute. Neurovascular Disorder. NCI Thesaurus. Code C117007.

A disorder of the nervous system related to a vascular etiology. 